\title{
The Penrose hypothesis in the 21st century: revisiting the asylum
}

\author{
Mark Toynbee
}

Department of Psychiatry, Oxford University, Warneford Hospital, Oxford, UK; marktoynbee@doctors.org.uk

ABSTRACT FROM: Mundt AP, Chow WS, Arduino M, et al. Psychiatric hospital beds and prison populations in South America since 1990: does the Penrose hypothesis apply? JAMA Psychiatry 2015;72:112-18.

\section{BACKGROUND}

About 80 years ago, Penrose proposed an inverse relationship between the relative number of psychiatric beds available to a population and its total number of prisoners, based on calculations from cross-sectional study of 18 countries. ${ }^{1}$ The subsequent drive for deinstitutionalisation that has dominated policy decisions in many countries for over half a century has provided a convenient natural experiment to test Penrose's hypothesis. In a large multinational cross-sectional study in $2004^{2}$ no association was demonstrated, supporting other work from the USA ${ }^{3}$ and Scandinavia. ${ }^{4}$ Recently macroeconomic factors have been suggested as more potent drivers of the relative sizes of psychiatric hospitals and prisons. However, none of the published studies have thus far sufficiently disproved Penrose's direct inverse association theory.

\section{METHODS OF THE STUDY}

This paper investigated psychiatric bed levels and prisoner numbers in South America since the Caracas Declaration in 1990, where South American countries committed to following a Western model of deinstitutionalisation and investment in community services. At least two separate researchers in 10 South American countries were asked by email to supply retrospective longitudinal data on the numbers of psychiatric beds and the size of prison populations between 1991 and 2011. Primary national data sources were used preferentially and if not available, secondary sources such as publications were used. Two multivariate regression analyses were conducted, with GNI (gross national income) and the Gini index (data from the World Bank) as covariates.

\section{WHAT DOES THIS PAPER ADD}

Mundt and colleagues demonstrated, based on multinational longitudinal data controlling for economic growth, an association between a reduction in psychiatric beds and an increase in prison population. All six countries where data were available showed a decrease in the number of psychiatric beds per head of population. Relative prison populations rose in all six countries over the same time period. This relative reduction in psychiatric beds was greatest where and when the prison populations increased. A positive association between economic growth and increased prison population was also demonstrated.

\section{STRENGTHS}

- Apparently the first paper to use multinational longitudinal data and control for macroeconomic confounders to investigate the Penrose hypothesis, which has important implications for health policy.

- The choices of location and time period, where the explicit aim of the countries involved was to move psychiatric care from institutions to the community, were both reasonable.

- The authors collated data over 20 years from six different countries, totalling over $70 \%$ of the population of Latin South America.

\section{LIMITATIONS}

- Whilst the total population covered by the data was significant, it was dominated by Brazil, and three of the most populous countries in South America were excluded due to lack of reliable data.

- The data sources were heterogenous resulting in total, in an average of 8.8 useable data points per country over the 20-year study period. As the authors point out, systematic national data collection would result in more data points leading to added robust and detailed analysis.

- The study controlled for two confounders. Other recent studies have controlled for over to 10, including health expenditure and urbanity, which may have been informative here. ${ }^{5}$

\section{WHAT NEXT IN RESEARCH}

Further longitudinal studies are necessary to confirm any direct causal relationship between relative numbers of psychiatric beds and prison populations. Studies that control for, among other things, investment in health and social care, reinstitution in other settings (eg, acute hospitals) and rates of violent crime would be particularly useful.

\section{TAKE HOME MESSAGES}

The authors conclude that since there is little appetite for a return of asylums, investment should continue to be focused on communitybased care. While broadly true, there is also an increasing recognition that the needs of a small but significant group of individuals with severe mental health problems whose illnesses are refractory to current management and who require long-term supported residential care are not being met. ${ }^{6-8}$ While deinstitutionalisation has benefited the majority of psychiatric patients, it has recently been argued that the most difficult to treat patients remain inadequately supported and eventually present to other, often inappropriate, institutions (eg, acute hospitals or prisons) or end up homeless. These results are the first multinational longitudinal evidence of an association between the number of psychiatric beds and prison population. As such, it adds weight to claims that underfunded community programmes led to ethically questionable, clinically inappropriate and economically expensive 'reinstitutionalisation' or 'criminalisation' of mental health patients in prisons poorly set up to help them. Policymakers should consider the limits of deinstitutionalisation.

Twitter Follow Mark Toynbee at @toynbeem

Competing interests None declared.

doi:10.1136/eb-2015-102115

Received 14 April 2015; Revised 12 May 2015; Accepted 28 May 2015

\section{REFERENCES}

1. Penrose LS. Mental disease and crime: outline of a comparative study of European statistics. Br J Med Psychol 1939;18:1-15.

2. Large MM, Nielssen 0. The Penrose hypothesis in 2004: patient and prisoner numbers are positively correlated in low-and-middle income countries but are unrelated in high-income countries. Psychol Psychother 2009;82:113-19.

3. Steadman HJ, Monahan J, Duffee B, et al. The impact of state mental hospital deinstitutionalization on United States prison populations, 1968-1978. J Crim Law Criminol 1984;75:474-90.

4. Hartvig $\mathbf{P}$, Kjelsberg E. Penrose's law revisited: the relationship between mental institution beds, prison populations and crime rate. Nord J Psychiatry 2009;63:51-6.

5. Wolf A, Gray R, Fazel S. Violence as a public health problem: an ecological study of 169 countries. Soc Sci Med 2014;104:220-7.

6. Lamb HR. Does deinstitutionalization causes criminalisation? The Penrose hypothesis. JAMA Psychiatry 2015;72:105-6.

7. Sisti DA, Segal AG, Emanuel EJ. Improving long-term psychiatric care: bring back the asylum. JAMA 2015;313:243-4.

8. Singh S. Investment in mental health: a battle for resources. Lancet Psychiatry 2015;2:3-5. 